1 Mcalpine D, Compston N. Some aspects of the natural history of disseminated sclerosis: incidence, course and prognosis; factors affecting onset and coursc. Q. J. Med 1952;21:135-67.

2 Confavreux C, Aimard G, Devic M. Course and prognosis of multiple sclerosis assessed by the computerized data processing of 349 patients. Brain 1980;103:281-300.

3 Weinshenker BG, Bass B, Rice GPA, et al. The natural history of multiple sclerosis: a geographical based study. 1. Clinical course and disability. Brain 1989:112:133-46

4 McAlpine D. The benign form of multiple sclerosis. A study based on 241 cases seen within three years of onset and followed up until the tenth year or cases seen within three years of onset and fol
more of the disease. Brain 1961;84:186-203.

5 Thompson AJ, Hutchinson M, Brazil J, et al. A clinical and laboratory studv of benign multiple sclerosis. Q F Med 1986;58:69-80.

6 McAlpine D. Course and prognosis in multiple sclerosis. In: McAlpine D, Lumsden CE, Acheson ED, eds. Multiple sclerosis: a reappraisal. Edinburgh Churchill Livingstone, 1972:206-7.

McDonald WI. Pathophysiology of multiple sclerosis. In: McDonald WI Silberberg DH, eds. Multiple sclerosis. London: Butterworths, 1986:128-9.

8 Stewart WA, Hall LD, Berry K, Paty DW. Correlation between NMR scan and brain slice data in multiple sclerosis. Lancet 1984;ii:412.

9 Ormerod IEC, Miller DH, McDonald WI, $t$ t al. The role of NMR imaging in the assessment of multiple sclerosis and isolated neurological lesions: quantitative study. Brain 1987:110:1579-616.
10 Poser CM, Paty DW, Schcinberg L, et al. New diagnostic criteria tor multiple sclerosis: guidetines for research protocols. Ann Neurol 1983;13:227-31.

11 Kurtzke JF. Rating neurologic impairment in multiple sclerosis: an expanded disability status scale (EDSS). Neurologv 1983:33:14+4-52.

12 Miller DH, Rudge P, Johnson (i, et al. Serial gadolinium enhanced magnetic resonance imaging in multiple sclerosis. Brain 1988;111:927-39.

13 Isaac C, L.i DKB, Genton M, et al. Multiple sclerosis: a serial study using MRI in relapsing patients. Neurologv 1988;38:1511-5.

14 Thompson AJ, Kermode AG, MacManus DG, Kingsley DPE, Moseles IF, MICDonald WI. Pathogenesis of progressive multiple sclerosis. Lance 1989;i:1322-3.

15 Koopmans RA, Li DKB, Grochowski E, Cutler PJ, Paty DW. Benign versus chronic progressive multiple sclerosis: magnetic resonance imaging features. Ann Neurol 1989;25:74-8

16 Kermode AG, Tofts PS, Thompson AJ, et al. Heterogeneity of blood-brain barrier changes in multiple sclerosis: an MRI study. Neurology (in press).

17 Kappos L, Stadt D, Rohrbach E, Keil W. Gadolinium-D'TPA enhanced magnetic resonance imaging in the evaluation of different discasc courses and discase activity in MS. Neurologv 1988;38 (Suppl 1):255.

18 Olerup (), Fredrikson S, Olsson T, Kam-Hansen H. HLA class II genes in chronic progressive and in relapsing/remitting multiple sclerosis. Lance 1987 ;ii:327.

19 McDonald WI. The diagnosis of multiple sclerosis. Br. Med f 1989:299:635-7.

\title{
Social influences and cardiovascular risk factors as determinants of plasma fibrinogen concentration in a general population sample of middle aged men
}

\author{
Annika Rosengren, Lars Wilhelmsen, Lennart Welin, Alecka Tsipogianni, \\ Ann-Catrin Teger-Nilsson, Hans Wedel
}

Abstract
Objective-To analyse the relation between fibrinogen concentration and social class and other social factors found to be related to mortality. The results regarding cardiovascular disease are unpublished, as yet.

Design-Cross sectional population study.

Setting-City of Gothenburg, Sweden.

Subjects -639 Men from a population sample of 1016 men aged 50 in 1983. They were all employed and had no history of myocardial infarction or stroke. Fibrinogen values were available for all of them.

Main outcome measure-Fibrinogen concentration in relation to socioeconomic state according to occupation, and other social influences determined as number of people in the household and scores of social activities and activities in and outside the house.

Results-Men with low scores for activities at home had a mean plasma fibrinogen concentration of $3.34 \mathrm{~g} / 1$ (95\% confidence interval 3.21 to 3.47$)$, whereas those with an intermediate score had a mean concentration of $3.16(3.00$ to 3.32$) \mathrm{g} / 1$ and those with a high score $3.02(2.95$ to 3.10$) \mathrm{g} / \mathrm{l}$. Similar inverse relations were noted for the two other activity scores and for occupational class (class 1 being unskilled and semiskilled workers and class 5 professionals and executives) and the number of people in the household. Smoking exerted a strong influence on fibrinogen concentration, the relations between fibrinogen concentration and social factors being evident only in non-smokers. The mean difference in fibrinogen value between the non-smokers with the lowest activity scores at home and those with the highest scores was $0.36(0.19$ to 0.54$) \mathrm{g} / \mathrm{l}$, and similar differences were seen for the two other activity scores. Multiple regression analyses showed smoking, body mass index, the sum of all activities (inverse relation), and diabetes to be independently associated with fibrinogen value, whereas occupational class $(p=0.81)$ and the number of people in the household $(p=0.09)$ were not.
Conclusions-Psychosocial influences secm te influence the coagulation system in the body in a way that is associated with cardiovascular disease and premature death.

\section{Introduction}

High plasma concentrations of fibrinogen have been found to be independently associated with increased risk of cardiovascular disease in longitudinal studies.' Fibrinogen has also been implicated in the inverse relation between social class and coronary heart discase that has been described in Sweden ${ }^{6}$ and other Western industrialised countries. ${ }^{78}$ Social class is, however, associated with a wide variety of other psychosocial variables, such as measures of social support and network indices. Job stress was found to be related to fibrinogen concentration and contributed substantially to the differences found in fibrinogen concentration between different occupational grades. ${ }^{5}$ We examined the relation between fibrinogen concentration and occupational class and other measures of social influences that were previously found to be related to mortality in another sample of middle aged men. ${ }^{9}$

\section{Subjects and methods}

STUDY POPULATION

In 1983 a random sample was drawn of half of all the men in Gothenburg who were born in 1933. The men in the sample $(n=1016)$, all of whom were aged 50 , were invited to a health examination. In all, $776 \mathrm{men}$, or $76 \%$ of the sample, responded.

\section{EXAMINATIONS}

All examinations were performed in the morning. Blood pressure was measured with a mercury sphygmomanometer in the sitting position after five minutes' rest. Body weight was measured on a lever balance to the nearest $0 \cdot 1 \mathrm{~kg}$. Body mass index was calculated as weight in $\mathrm{kg} /$ (height in metres)?

To determine plasma fibrinogen concentrations 
blood samples were drawn after an overnight fast from an antecubital vein without stasis into vacuum tubes containing trisodium citrate $0 \cdot 13 \mathrm{~mol} / 1$, one volume for nine volumes of blood. Plasma was prepared, frozen, and stored at $-70^{\circ} \mathrm{C}$ for up to one year. Fibrinogen in plasma was measured with a polymerisation method as originally described by Clauss. ${ }^{10}$ Plasma was diluted with buffer in the ratio of one to 15 and an aliquot $(0.2 \mathrm{ml})$ was added to the cuvettes of a Coag-a-mate dual channel analyser (Organon Teknika, Durham, North Carolina; early in the study Warner-Lambert, Levitown, Pennsylvania). An aliquot $(100 \mu \mathrm{l})$ of thrombin (Topostasine, 400 National Institute of Health units/ml; Roche, Switzerland) was automatically added by the machine and the clotting time measured optically. Usually four parallel measurements were made. The method was standardised by a reference curve constructed from plasma samples containing known fibrinogen concentrations. The error of the method, expressed as coefficient of variance for control plasma samples, was $8 \%$. For technical reasons fibrinogen values were available in only 672 subjects. Plasma cholesterol and triglyceride concentrations were determined according to standard laboratory procedures.

Before the examination all participants had completed a postal questionnaire, and the answers were checked by the examining physician. Smoking habits were classified as (a) non-smokers; (b) ex-smokers of more than a month's duration, $(c)$ smokers of $1-14 \mathrm{~g}$ tobacco every day, $(d)$ smokers of $15-24 \mathrm{~g} /$ day, and $(e)$ smokers of $\geqslant 25 \mathrm{~g} /$ day. A cigarette was considered to contain $1 \mathrm{~g}$ tobacco, a cigarillo $2 \mathrm{~g}$, and a cigar $5 \mathrm{~g}$. Pipe smokers were coded according to the amount of tobacco used. Physical activity during leisure time was coded according to a four point scale, with 1 representing sedentary activity and 4 representing regular, extremely strenuous activity. Psychological stress (defined as feeling tense, irritable, or nervous) was graded from 1 (never experienced stress) to 6 (a permanent feeling of stress during the previous five years). Men who answered the question "Do you have diabetes?" in the affirmative were classified as diabetics. Treatment of hypertension was also inquired into.

Occupation was coded according to the socioeconomic classification system elaborated by the

TABLE I-Plasma fibrinogen concentrations by smoking category. Values are means ( $95 \%$ confidence intervals)

\begin{tabular}{ll}
\hline Smoking category & Fibrinogen $(\mathrm{g} / \mathrm{l})$ \\
\hline Never smoked $(\mathrm{n}=244)$ & $2 \cdot 96(2 \cdot 87$ to 3.05$)$ \\
Ex-smoker $(\mathrm{n}=163)$ & $2 \cdot 99(2 \cdot 88$ to $3 \cdot 11)$ \\
Smokers $(\mathrm{g}$ tobacco/day $):$ & $3.28(3 \cdot 10$ to 3.46$)$ \\
$1-14(\mathrm{n}=100)$ & $3.50(3.36$ to 3.65$)$ \\
$15-24(\mathrm{n}=99)$ & $3.32(3.07$ to 3.57$)$ \\
$>24(\mathrm{n}=33)$ & 0.0001 \\
$\mathrm{p}$ Value for trend & \\
\hline
\end{tabular}

TABLE II-Plasma fibrinogen concentrations by smoking, occupational class, and number of people in household. Values are means ( $95 \%$ confidence intervals)

\begin{tabular}{|c|c|c|c|}
\hline & Non-smokers $(n=407)$ & Smokers $(\mathbf{n}=232)$ & Total $(n=639)$ \\
\hline \multicolumn{4}{|c|}{ Occupational class ${ }^{\star}:$} \\
\hline $1(n=114)$ & $3.09(2.93$ to 3.25$)$ & $3.29(3.02$ to 3.57$)$ & $3 \cdot 16(3.01$ to $3 \cdot 30)$ \\
\hline $2(n=155)$ & $3.04(2.89$ to 3.20$)$ & $3.35(3.17$ to 3.52$)$ & $3.18(3.06$ to 3.30$)$ \\
\hline $3(n=97)$ & $2.92(2.75$ to 3.09$)$ & $3.47(3.20$ to 3.74$)$ & $3.15(2.99$ to 3.31$)$ \\
\hline $4(n=135)$ & $2.95(2.79$ to 3.12$)$ & $3.62(3.36$ to 3.88$)$ & $3.17(3.02$ to 3.32$)$ \\
\hline $5(n=112)$ & $2.81(2.69$ to 2.94$)$ & $3.20(2.90$ to 3.49$)$ & $2.92(2.79$ to 3.04$)$ \\
\hline Mean difference $\dagger$ & $0.27(0.07$ to 0.48$)$ & $0.10(-0.31$ to 0.50$)$ & $0.24(0.05$ to 0.43$)$ \\
\hline $\mathrm{p}$ Value for trend & 0.010 & 0.56 & 0.031 \\
\hline \multicolumn{4}{|c|}{ No of people in household $\$$ : } \\
\hline $1(n=110)$ & $3 \cdot 19(2.99$ to 3.39$)$ & $3.35(3.14$ to 3.55$)$ & $3 \cdot 26(3 \cdot 12$ to $3 \cdot 41)$ \\
\hline $2(n=193)$ & $2.96(2.84$ to 3.08$)$ & $3.58(3.36$ to 3.80$)$ & $3 \cdot 15(3.04$ to 3.27$)$ \\
\hline $3(n=169)$ & $3.03(2.88$ to $3 \cdot 18)$ & $3.27(3.06$ to 3.48$)$ & $3.11(2.99$ to 3.23$)$ \\
\hline$\geqslant 4(n=145)$ & $2.81(2.68$ to 2.94$)$ & $3.25(3.04$ to 3.46$)$ & $2.97(2.85$ to 3.08$)$ \\
\hline Mean difference $†$ & $0.38(0.14$ to 0.62$)$ & $0 \cdot 10(-0 \cdot 19$ to 0.39$)$ & $0.30(0.11$ to 0.48$)$ \\
\hline p Value for trend & $0 \cdot 007$ & $0 \cdot 18$ & 0.002 \\
\hline
\end{tabular}

Central Bureau of Statistics in Sweden." This classification, in the aggregated form used in this study, consists of five occupational classes: unskilled and semiskilled workers (1); skilled workers (2); foremen in industrial production and assistant non-manual employees (3); intermediate non-manual employees (4); and employed and self employed professionals, higher civil servants, and executives (5). Note that the order is the opposite to that of many other classifications. Non-professional self employed subjects were classified separately.

During the examination the participants completed a detailed questionnaire about social variables. ${ }^{9}$ They were asked about the number of people in their household (including themselves) and activities during the previous year. Activities were divided into activities at home (repairs, hobbies, studying, reading, gardening, painting, maintenance of cars and boats, sauna bathing, using an exercise bicycle); activities outside the home (swimming, cycling, skiing, skating, hunting or fishing, mushroom or berry picking, going to the cinema, theatre, concerts, sports and horse racing events, visiting restaurants and museums, travelling abroad or in Sweden, going to church); and social activities (parties at home, organised sport, dancing, visiting relatives or friends, attending trade union or other association meetings or study circles). The responses never, occasionally, and often or regularly were given a score of 0,1 , and 2 respectively. The ratings for each question were summed to give a theoretical range for activities at home of 0-20 points. for activities outside the home of $0-28$ points, and for social activities of 0-16 points." In the multivariate analyses a sum of all activities was entered, with a theoretical range of 0-64.

All men with a history of having been admitted to hospital for myocardial infarction or stroke were excluded from the analyses, as were men with disability pensions. All analyses are based on the remaining 639 men, who were all employed and without known major cardiovascular disease.

\section{STATISTICAL METHODS}

Correlations between fibrinogen concentration and continuous or graded variables were tested according to the method of Pearson, and the $p$ values for the tests are given in addition to means and $95 \%$ confidence intervals. The difference between the lowest and the highest scores was calculated for each of the activity scores and for occupational class and number of people in the household, and the values are given with $95 \%$ confidence intervals. For the activity scores the tests were performed using the entire ranges of $0-20,0-28$, and $0-16$ for the three scores. Multiple regression analyses were performed with fibrinogen concentration as the dependent variable.

\section{Results}

Mean plasma fibrinogen concentration for all the men in the population (after removal of men with previous myocardial infarction or stroke and men with disability pensions) was $3 \cdot 12 \mathrm{~g} / \mathrm{l}(\mathrm{SD} 0.78 \mathrm{~g} / \mathrm{l})$.

There was a strong relation between fibrinogen concentration and smoking (table I). Those who had never smoked did not differ from ex-smokers in terms of fibrinogen concentration. There was no obvious dose-response relation among the current smokers between fibrinogen concentration and the amount of tobacco smoked.

Significant inverse relations were found between fibrinogen concentration and occupational class and the number of people in the household (table II). As smoking was more prevalent among the lower occupational classes as well as among subjects living 
alone, data for current non-smokers and smokers are presented separately. Table II shows that the relations between fibrinogen concentration and occupational class and the number of people in the houschold were restricted to non-smokers. The mean difference between non-smoking men in the lowest occupational class and those in the highest was 0.27 ( $95 \%$ confidence interval 0.07 to 0.48$) \mathrm{g} / \mathrm{l}$, whereas the mean difference between non-smoking men living alone and men living in households of four or more people was $0.38(0.14$ to $0.62) \mathrm{g} / \mathrm{l}$

Fibrinogen concentration was significantly and inversely related to all of the three activity scores in a dose-response fashion (table III). Just as for occupational class and the number of people in the household, this association was confined to nonsmokers. The mean difference between uon-smoking men with low scores and those with high scores ranged from $0.27(0.09$ to 0.45$) \mathrm{g} / \mathrm{l}$ to $0.36(0.19$ to 0.54$) \mathrm{g} / \mathrm{l}$.

Plasma fibrinogen concentration was not related to systolic blood pressure or to treatment for hypertension $(\mathrm{r}=0.02, \mathrm{p}=0.64$ and $\mathrm{r}=0.05, \mathrm{p}=0.22$, respectively). Fibrinogen concentration in diabetics $(n=23)$ was significantly higher than that in non-diabetics (mean fibrinogen concentration in diabetics $3.58(3.19$ to $3.97) \mathrm{g} / \mathrm{l}$ compared with $3 \cdot 10(3.04$ to $3 \cdot 16)$ in nondiabetics; $p=0 \cdot 004)$. Small but significant correlations were found between fibrinogen concentration and plasma cholesterol concentration, body mass index and physical activity (inverse relation). No relation was found between fibrinogen concentration and stress score $(r=0 \cdot 04, p=0 \cdot 26)$

As there were significant interrelations between several of the variables associated with fibrinogen concentration multivariate regression analyses were performed with fibrinogen concentration as the dependent variable and smoking, plasma cholesterol

TABLE III - Plasma fibrinogen concentrations by smoking and scores ${ }^{\star}$ for social activity and activity at and outside home. Values are means ( $95 \%$ confidence intervals)

\begin{tabular}{|c|c|c|c|}
\hline Activity score & Non-smokers $(n=407)$ & Smokers $(\mathrm{n}=232)$ & Total $(n=639$ \\
\hline \multicolumn{4}{|c|}{ At home (range $0-20) \dagger$ : } \\
\hline $0-5(n=156)$ & $3 \cdot 24(3.09$ to $3 \cdot 39)$ & $3.46(3.25$ to 3.67$)$ & $3.34(3.21$ to $3 \cdot 47)$ \\
\hline $6-7(n=102)$ & $3.04(2.85$ to 3.23$)$ & $3 \cdot 36(3.08$ to 3.63$)$ & $3 \cdot 16(3.00$ to $3 \cdot 32)$ \\
\hline$>7(n=380)$ & $2.87(2.78$ to 2.96$)$ & $3.34(3.21$ to 3.48$)$ & $3.02(2.95$ to $3 \cdot 10)$ \\
\hline Mean difference $\ddagger$ & $0.36(0.19$ to 0.54$)$ & $0.12(-0.13$ to $0 \cdot 37)$ & $0.32(0.17$ to 0.47$)$ \\
\hline p Value for trend & 0.0007 & $0 \cdot 21$ & 0.0001 \\
\hline \multicolumn{4}{|c|}{ Outside home (range 0-28): } \\
\hline $0-6(n=160)$ & $3.23(3.05$ to 3.41$)$ & $3.44(3.25$ to 3.64$)$ & $3.34(3.20$ to $3 \cdot 47)$ \\
\hline $7-8(n=105)$ & $3.01(2.85$ to 3.17$)$ & $3.29(3.06$ to 3.52$)$ & $3 \cdot 12(2 \cdot 98$ to $3 \cdot 25)$ \\
\hline$>8(\mathrm{n}=374)$ & $2.89(2.80$ to 2.98$)$ & $3.37(3.22$ to 3.52$)$ & $3.03(2.96$ to 3.11$)$ \\
\hline Mean difference & $0.34(0.14$ to 0.54$)$ & $0.07(-0.18$ to 0.32$)$ & $0.30(0.15$ to 0.46$)$ \\
\hline $\mathrm{p}$ Value for trend & 0.008 & 0.56 & 0.001 \\
\hline \multicolumn{4}{|l|}{ Social (range $0-16$ ) $)$ : } \\
\hline $0-4(n=180)$ & $3 \cdot 14(2 \cdot 99$ to $3 \cdot 28)$ & $3.41(3.23$ to 3.60$)$ & $3 \cdot 26(3 \cdot 14$ to $3 \cdot 38)$ \\
\hline $5-6(n=191)$ & $3.00(2.87$ to 3.13$)$ & $3.25(3.08$ to 3.43$)$ & $3 \cdot 10(2.99$ to 3.21$)$ \\
\hline$>6(n=266)$ & $2.87(2.77$ to 2.97$)$ & $3.48(3.29$ to 3.66$)$ & $3.04(2.94$ to 3.13$)$ \\
\hline Mean difference $\neq$ & $0.27(0.09$ to 0.45$)$ & $-0.06(-0.32$ to 0.20$)$ & $0.23(0.08$ to 0.38$)$ \\
\hline $\mathrm{p}$ Value for trend & $0 \cdot 070$ & $0 \cdot 87$ & 0.036 \\
\hline
\end{tabular}

$\star_{0}=$ Never, $1=$ occassionally, $2=$ often or regularly.

tData missing for one subject.

Data missing for two subjects.

TABLE IV-Multiple regression analyses of fibrinogen concentration in relation to social and other variables

\begin{tabular}{|c|c|c|c|c|c|c|}
\hline & \multicolumn{3}{|c|}{ Including occupational class ${ }^{\star}$} & \multicolumn{3}{|c|}{$\begin{array}{l}\text { Including occupational class, No } \\
\text { of people in household, and total score } \\
\text { of activities }\end{array}$} \\
\hline & $\begin{array}{l}\text { Regression } \\
\text { coefficient }\end{array}$ & SE & $\mathrm{p}$ Value & $\begin{array}{l}\text { Regression } \\
\text { coefficient }\end{array}$ & SE & $\mathrm{p}$ Value \\
\hline Intercept & $3 \cdot 74$ & 0.43 & $0 \cdot 0001$ & $4 \cdot 29$ & $0 \cdot 47$ & 0.0001 \\
\hline Smoking $($ no $=0 ;$ yes $=1$ ) & 0.42 & 0.064 & 0.0001 & $0 \cdot 38$ & 0.065 & 0.0001 \\
\hline Plasma cholesterol $(\mathrm{mmol} / \mathrm{l})$ & 0.037 & 0.027 & $0 \cdot 18$ & 0.050 & 0.027 & 0.070 \\
\hline Body mass index $\left(\mathrm{kg} / \mathrm{m}^{2}\right)$ & 0.030 & 0.009 & 0.0009 & 0.029 & 0.009 & 0.001 \\
\hline Physical activity (score 1-4) & -0.066 & 0.049 & $0 \cdot 18$ & $-0 \cdot 009$ & 0.053 & 0.86 \\
\hline Diabetes $($ no $=0 ;$ yes $=1)$ & 0.37 & $0 \cdot 16$ & 0.021 & $0 \cdot 43$ & $0 \cdot 17$ & 0.012 \\
\hline Occupational class $(1-5)$ & -0.025 & 0.022 & 0.25 & -0.005 & 0.023 & 0.81 \\
\hline No of people in household $(1-\geqslant 4)$ & & & & -0.049 & 0.029 & 0.094 \\
\hline Total activity score $(0-64)^{\prime} \dagger$ & & & & $-0 \cdot 010$ & 0.004 & 0.009 \\
\hline
\end{tabular}

^In addition to smoking, cholesterol concentration, body mass index, physical activity during leisure time, and diabetes.

tSum of activities at home and outside home and of social activities. concentration, body mass index, diabetes, physical activity during leisure time, occupational class, and the number of people in the household as independent variables. The activity scores were highly intercorrelated $(r=0.49-0.56 ; p<0.001)$, and for the purpose of the present analyses the score of $0-2$ for the 32 different activities was summed, yielding a theoretical range of $0-64$, with 0 representing no activities and 64 the maximum number. Table IV shows that occupational class was not independently associated with fibrinogen concentration $(p=0 \cdot 25)$, even when no other social variables were included. When the number of people in the household was included in addition to occupational class the number of people in the household was significantly associated with fibrinogen concentration (regression coefficient $=-0.059, \mathrm{p}=0.046$; data not shown, but when the total activity score was added the relation between the number of people in the household and fibrinogen concentration was no longer significant $(p=0.094)$. The total activity score was significantly related to fibrinogen concentration, independently of all other variables included in the analysis $(p=0 \cdot 009)$. Substituting activities at or outside the home for the total sum of activities yielded regression coefficients of -0.023 and -0.022 , respectively ( $p=0.009$ and 0.008 ), whereas the social activity score did not have an independent effect (regression coefficient $=-0.005$, $p=0 \cdot 67$ )

As the differences in fibrinogen concentration were restricted to non-smokers only, fibrinogen values adjusted for plasma cholesterol concentration, body mass index, physical activity, and diabetes were calculated for the three activity scales in non-smokers. For activities at and outside the home there was no change in the mean differences between the lowest and the highest corres after this adiustment, whereas a minimal decteace was noted for the social activity scale, from $0.2 .2100 .25 \mathrm{~g} / \mathrm{l}$

\section{Discussion}

We found plasma fibrinogen concentration to be inversely related to measures of social activity, a higher score of social activity being associated with a lower fibrinogen concentration. Though these variables might be considered to be crude and subject to individual interpretation by the study participants, an identical measurement scale was shown to predict mortality in a previous sample of men aged 50 in Gothenburg. ${ }^{4}$ Little is known about the mechanisms whereby social factors are associated with substantial differences in health and risk of premature death. ${ }^{12}$

Fibrinogen is associated with cardiovascular disease and death..$^{1-4}$ Most prospective studies on social network factors have dealt with the impact of social support on mortality from all causes and not particularly on mortality from cardiovascular disease. A more recent follow up of the men born in 1913 and 1923 has, however, shown a significant association between the activity scales and death from cardiovascular disease (Welin, unpublished data). Other authors have also found death from cardiovascular disease ${ }^{13}$ and the prevalence of coronary heart disease ${ }^{14}$ to be correlated with indices of social support. The association between low socioeconomic state and coronary heart disease is well known. ${ }^{6-k}$ Fibrinogen, on the other hand, has been associated with death from all causes as well. ${ }^{2}$ Our findings are consistent with a hypothesis that social variables influence fibrinogen concentrations in the blood and thereby the risk of cardiovascular disease.

We measured the concentration of functionally active fibrinogen. In healthy subjects this closely correlates with the fibrinogen concentration measured by other methods. The functionally active fibrinogen concentration is probably the most important of the 
two variables in the prediction of cardiovascular disease.

The pathogenetic mechanisms behind the association between fibrinogen concentration and cardiovascular disease include effects on plasma viscosity ${ }^{15}$ and platelet aggregation. ${ }^{16}$ Furthermore, local deposition of fibrin may be more pronounced and the fibrinolysis less efficient with higher fibrinogen values. These mechanisms may all promote thrombogenesis, apart from any role of fibrinogen in the local formation of thrombus.

The obvious confounding factor in the association between any measurement of social support and an adverse health outcome or, as in our study, altered composition of the blood is previous poor health. Nevertheless, the effect of social support on mortality has generally been shown to be independent of baseline health state. ${ }^{9718}$ In our study all subjects were employed and essentially healthy. Diabetes may cause plasma fibrinogen concentration to increase, ${ }^{19}$ but the association between fibrinogen concentration and social activities persisted even after controlling for diabetes.

The relation between smoking and fibrinogen concentration is well known ${ }^{20-22}$ and was seen in our study so clearly that all other influences on fibrinogen concentration were practically obliterated among the smokers. We found no suggestion of a dose-response relation between fibrinogen concentration and the amount of tobacco smoked. This agrees with previous results from the study of men born in $1913^{20}$ but not with other data. ${ }^{22}{ }^{23}$ Our data from the primary prevention study also do not suggest a dose-response relation between the incidence of coronary heart disease and smoking. ${ }^{24}$ The increase in risk of coronary heart disease among smokers is probably mediated in part by fibrinogen. A quarter to a half of the effect of smoking on the risk of atherothrombotic cardiovascular disease might he attributed to the effect of smoking on fibrinogen concentrations."

We found no independent association between fibrinogen concentration and occupational class, which applied even when no other social variables were entered into the multivariate analyses. In a previous prospective study that used the same classification the inverse relation between the incidence of coronary heart disease (but not stroke) and occupational class was consistent. ${ }^{6}$ The association between fibrinogen concentration and various psychosocial variables is probably complex. The matter is complicated further by a lack of objective criteria for the measurement of the social standing of a person in society. Possibly, the Swedish socioeconomic classification differentiates between different social levels less well than its British counterpart. It is noteworthy that among the individual activities that had significant associations with fibrinogen concentration were items that require the possession of property, such as maintenance of cars and boats and doing repairs in the house. Activities associated with the arts, such as going to the theatre or visiting museums and exhibitions, were also associated with a decrease in fibrinogen concentration. Subjects active in physical pursuits also had lower fibrinogen values than those who did not, even though physical activity in itself was not independently associated with fibrinogen concentration. Possibly, those activities which were inversely associated with fibrinogen concentration are better indicators of social class than occupation. Or they may measure network factors and also the level of integration into the community.

A job stress score was found to be related to fibrinogen value by Markowe et al and postulated to constitute part of the pathway between low social class and raised fibrinogen concentration. ${ }^{5}$ Our data do not include any measure of job stress. Stress, which in the present study was defined as a feeling of tension and anxiety, was not found to be associated with fibrinogen concentration. Nevertheless, this way of measuring stress may be too inaccurate to provide good information and hence we may not have been able to control adequately for the influence of stress. Short term stress has been shown to induce raised fibrinogen concentrations in beef calves. ${ }^{25}$

Another possibility is that social influences may determine what people eat, and in a way that is not apparent from differences in plasma lipid concentrations. Low intake of antioxidant vitamins has been associated with ischaemic heart disease and cancer. ${ }^{26}$ Few data are available on the influence of diet on fibrinogen concentration, but diet is a possible confounder in the relation between social factors and fibrinogen. Vitamin concentrations in frozen plasma samples from the men in our study will be analysed. In addition, we are currently planning another study on cardiovascular risk factors that will help to clarify the relation between diet and fibrinogen concentration.

Alcohol may also be a confounder of the relation between social factors and fibrinogen concentration. Isolated and inactive people might tend to have alcohol problems to a higher extent than active and well integrated people. Non-drinkers have been shown, however, to have higher fibrinogen values than drinkers, ${ }^{27}$ and in another study no relation between alcohol consumption and fibrinogen concentration was found. ${ }^{28}$

It must be recognised that a crude and subjective measurement like the activity score will be particularly prone to confounding by various factors that have not been identified so far. The magnitude of the differences found suggests, however, that psychosocial influences on mortality and cardiovascular disease may, just as for smoking, in part be mediated through fibrinogen. Our findings need to be confirmed by further investigation, and prospective data are needed to estimate more accurately the role of fibrinogen in this context.

This study was supported by the Swedish Medical Research Council, the Swedish National Association against Heart and Chest Diseases, the Gothenburg Medical Society, and the Knut and Alice Wallenberg Foundation.

I Wilhelmsen L, Svärdsudd K, Korsan-Bengtsen K, Larsson B, Welin L, Tibblin $G$. Fibrinogen as a risk factor for stroke and myocardial infarction. Tibblin G. Fibrinogen as a risk

2 Meade TW, Mellows S, Brozovic M, et al. Haemostatic function and ischaemic heart disease: principal results of the Northwick Park heart study. Lance heart disease: 1986;ii:533-7.

3 Stone MC, Thorp JM. Plasma fibrinogen-a major coronary risk factor. $\mathcal{F} R$ Coll Gen Pract 1985;35:565-9.

+ Kannel WB, Wolf PA, Castelli WP, D'Agostino RB. Fibrinogen and risk of cardiovascular disease. The Framingham study. FAMA 1987;258:1183-6.

5 Markowe HLJ, Marmot MG, Shipley MJ, et al. Fibrinogen: a possible link between social class and coronary heart disease. Br Med f 1985;291:1312-4

6 Rosengren A, Wedel H, Wilhelmsen L. Coronary heart disease and mortality among men from different occupational classes in Sweden. Br Med $f$ 1988;297:1497-1500.

7 Marmot MG, Shipley MJ, Rose G. Inequalities in death-specific explanations of a general pattern? Lancet $1984 ;$; : $1003-6$.

8 Holme I, Helgeland A, Hjermann I, Leren P, Lund-Larsen PG. Four-year mortality by some socioeconomic indicators: the Oslo study. $\mathcal{I}$ Epidemiol Community Health 1980:34:48-52.

9 Welin L, Tibblin G, Stärdsudd K, et al. Prospective study of social influences on mortality. The study of men born in 1913 and 1923. Lancet 1985:i:915-8.

10 Clauss A. Gerinnungsphysiologische Schnellmethode zur Bestimmung des Fibrinogens. Acta Haematol (Basel) 1957;17:237.

11 Swedish Central Bureau of Statistics. Swedish socio-economic classification Stockholm: Statistics Sweden, 1982.

12 House JS, Landis KR, Umberson D. Social relationships and health. Science 1988;241:540-5.

13 Orth-Gomér K, Johnson JV. Social network interaction and mortality. A six year follow-up study of a random sample of the Swedish population. 7 Chronic Dis 1987; 40:949-57.

14 Reed D, McGee D, Yano K, Feinleib M. Social networks and coronary hear disease among Japanese men in Hawaii. Am $\mathcal{F}$ Epidemiol 1983;117:384-96.

15 Lowe GDO, Drummond MM, Lorimer AR, et al. Relation between extent of Lowe GDO, Drummond MM, Lorimer AR, et al. Relation betwcen
coronary artery disease and blood viscosity. Br Med f 1980;i:673-4.

16 Meade TW, Vickers MV, Thompson SG, Stirling Y, Haines AP, Miller GJ. Epidemiological characteristics of platelet aggregability. Br Med f 1985 , 290:428-32.

17 Berkman LF, Syme L. Social networks, host resistance and mortality: a nineyear follow-up study of Alameda County residents. Am $\mathcal{F}$ Epidemio 1979;109:186-204.

18 House JS, Robbins C, Metzner HL. The association of social relationships and activities with mortality: prospective evidence from the Tecumseh com munity health study. Am f Epidemiol 1982;116:123-40. 
19 Fuller JH, Keen H, Jarrett RJ, et al. Haemostatic variables associated with diabetes and its complications. Br.Med f 1979;ii:964-6.

20 Korsal-Bengten $K$, Wilhelmsen $L$, Tibblin $G$. Blood coagulation and fibrings in a $K$, Wikd

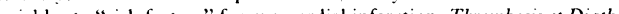
Haemorrhagica 1972;28:99-108.

21 Meade TW, Imeson J, Stirling Y. Effects of changes in smoking and other characteristics on clotting factors and the risk of ischaemic heart disease. Lancet 1987;ii:986-8.

22 Kannel WB, D'Agostino RB, Belanger AJ. Fibrinogen, cigarette smoking and risk of cardiovascular disease: insights from the Framingham study Am Heart f 1987; 113:1006-10.

23 Wilkes HC, Kelleher C, Meade TW. Smoking and plasma fibrinogen. Lancet $1988 ;: ; 07-8$

24 Wilhelmsen L. Coronary heart disease: epidemiology of smoking and intervention studies of smoking. Am Hearl f 1988;115:242-9.
25 Phillips WA. The effect of assembly and transit stressors on plasma tibrinogen concentration of beef calves. Canadian Journal of Comparative Medicin 1984:48:35-41.

26 Gey KF, Brubacher GB, Stähelin HB. Plasma levels of antioxidant vitamins in relation to ischemic heart disease and cancer. Am f Clin Nutr 1987:45:1368 77 .

27 Meade TW, Chakrabarti R, Haines AP, North WRS, Stirling Y. Characteristics involving fibrinolytic activity and plasma fibrinogen concentrations. BrMed F 1979;i:153-6.

28 Balleisen L, Bailey J, Epping PH, Schulte H, van de Loo J. Epidemiologica study on factor VII, factor VIII and fibrinogen in an industrial population. I. Baseline data on the relation to age, gender, body-weight, smoking, alcohol, pill-using and menopause. Thromb Haemost 1985;54:475-9.

(Accepted 3 fanuary 1990)

\title{
Implications of inflammatory changes on cervical cytology
}

\author{
Janet D Wilson, Angela J Robinson, Sheila A Kinghorn, David A Hicks
}

\begin{abstract}
Objective-To assess premenopausal women with inflammatory changes on cervical cytology for genital infections and cervical abnormalities.

Design-Prospective study of women attending general practice and family planning clinics who had a recent cervical cytology result with inflammatory changes.

Setting-Department of genitourinary medicine.

Patients-102 Premenopausal women with recent cytology result showing inflammatory changes and with no history of antibiotic or antifungal treatment since their smear.
\end{abstract}

Investigations-Genital examination and microbiological screening for genital infections; colposcopic examination about six weeks later.

Main outcome measures-Detection of genital infections, particularly those sexually acquired, and abnormalities on colposcopy.

Results-Genital infections were isolated in 77 patients, and one or more sexually acquired infections were found in 22. Prevalence of sexually acquired infections was significantly correlated with younger age (particularly being under 25), being single, separated, or divorced; using non-barrier contraception; and recent change of sexual partner. An abnormality on colposcopy was found in 36 women. There was a strong correlation of a sexually acquired infection with an abnormality at colposcopy; hence younger women were more likely to have a colposcopic abnormality.

Conclusions -Inflammatory changes on cytology are often associated with the presence of a sexually acquired infection and premalignant disease of the cervix, particularly in younger, single women using non-barrier contraception.

Department of

Genitourinary Medicine, Royal Hallamshire Hospital, Sheffield S10 2JF

Janet D Wilson, MRCP consultant

Angela J Robinson, MRCP,

senior registrar

David A Hicks, MRCOG, consultant

Eckington Health Centre, Sheffield S31 9BD

Sheila A Kinghorn, MRCGP, principal

Correspondence to: $\mathrm{Dr}$ Wilson

Br Med f 1990;300:638-40 patients who have inflammatory results of cervical cytology have been cited recently ${ }^{12}$ but these studies did not include comprehensive screening for genital infections or look at specific demographic details that might suggest high risk factors. The purpose of our study was to assess the significance of inflammatory changes on cervical smears taken as part of a routine community screening programme in regard to the presence of genital infections and the findings of colposcopy. Certain demographic details were documented to ascertain risk factors for the presence of sexually transmitted diseases or abnormalities on colposcopy.

\section{Patients and methods}

The study took place over a 12 month period. Patients were from three general practice areas (covered by 11 family practitioners) or from a community family planning clinic and had varying social and educational backgrounds.

All patients had had routine three or five yearly cervical smears taken at the practice or family planning clinic and the result had been reported as on cytology form HMR 101/5 (1982) showing inflammatory changes (box 24, 1). In some cases there was also a report of an inadequate specimen or negative results (box 23,1 or 2), but in others no comment had been made on evidence of a neoplastic pattern.

Women were excluded from the study if they had received antibiotic or antifungal treatment since their smear had been taken or if they were post menopausal (to avoid inflammatory changes due to oestrogen depletion).

GENITOURINARY EVALUATION AND SPECIMEN COLLECTION

All patients were referred to the department of genitourinary medicine where a full genitourinary history and examination were performed. A bivalve vaginal speculum was inserted and vaginal specimens collected for microscopy and culture of Gardnerella vaginalis, Candida albicans, Trichomonas vaginalis, and mycoplasmas. Cervical and urethral specimens were collected for microscopy and culture for Neisseria gonorrhoeae and for Chlamydia trachomatis enzyme immunoassay. Serum was collected for serological tests for syphilis. If genital vesicles or ulcers were present swabs were taken from the skin lesions and from the cervix for culture for herpes simplex virus. Genital warts were diagnosed by clinical appearances.

\section{LABORATORY METHODS}

Neisseria gonorrhoeae-Gram stained urethral and 